\title{
ILLUMINANCE MAPPING OF NIGHTTIME ROAD ENVIRONMENT USING UNMANNED AERIAL SYSTEM
}

\author{
R. T. Bahia ${ }^{1, *}$, M.C.Estur ${ }^{1, *}$, A.C. Blanco ${ }^{1,2}$, M. Soriano ${ }^{3}$ \\ ${ }^{1}$ Department of Geodetic Engineering, University of the Philippines-Diliman \\ *(roelbahia126, myralaikaestur)@gmail.com \\ ${ }^{2}$ Training Center for Applied Geodesy and Photogrammetry, University of the Philippines-Diliman \\ ${ }^{3}$ National Institute of Physics, University of the Philippines-Diliman
}

\section{Commission IV}

KEY WORDS: 3D Model, Calibration, Linear Regression, Photogrammetry, Road Lighting

\begin{abstract}
:
One purpose of road lighting in night-time environment is to allow pedestrians safe passage and provide sense of security. To attain this purpose, guidelines are set to make sure that proper lighting are present in roads. Current mapping of road lighting in the Philippines is a tedious process. To address this issue, an alternative method of mapping illuminance using Unmanned Aerial System is developed. A 3D model of the road was created using overlapping images and is the basis of the data points. The results of the calibration show that each of the camera channels, as well the photopic luminance value denoted as ND, shows a linear trend with the illuminance value recorded within the subject area having a range of 0.17 to 15 lux. Linear regression models using each of the channels of the camera and ND can be used to calculate illuminance with RMSE of less than 0.6 lux. It also shows that all values calculated from all regression models exhibits similar trend with blue differing by being generally lower in value. With blue as the best linear regression model, 3D and 2D models of illuminance were created. With these results, it can be concluded that application of photogrammetry through UAVmounted camera can be used to map illuminance at low level lighting.
\end{abstract}

\section{INTRODUCTION}

Road lighting has three main purposes: to allow all road users to proceed safely, to allow pedestrians safe passage and sense of security, and "to improve day-time and night-time appearance of the environment". Guidelines are established where criteria of road lighting depend on the measurement of luminance, illuminance, and their uniformity as criteria for standard lighting (CIE, 2010). In this work, illuminance measurement is considered for measuring and mapping road lighting. Illuminance pertains to the measure of light falling on a surface, measured in lux (Hiscocks, 2014). In the Philippines, roadway lighting guidelines are created by the Department of Energy. Their evaluation mapping of roadway illuminance involves measurement of illuminance using lux meter on certain intervals, which is then mapped as contours in the spreadsheet (DOE, n.d.). This method is tedious for large scale mapping and presents lower accuracy when done with higher intervals. This calls for a more efficient method of mapping of roadway lighting such as the use of photogrammetry.

Photogrammetry is a 3-dimensional measuring technique that uses overlapping photographs to measure points on the ground (SBL, 2015). Photogrammetry evolves from terrestrial, usage of cameras on the ground, to aerial photogrammetry where cameras and/or other sensors are mounted on an aircraft. Aerial photography today offers efficiency as it is easy to use and can deliver results rapidly with high accuracy (Agriculture Drone..., n.d.). Photogrammetry continues to develop over time. New applications of photogrammetry include crime detection, restoration of architectural treasures and other 3D modelling applications (Whitmore, n.d.). These 3D modelling can be done easily through the use of 3D modelling software such as Pix 4d Mapper and Agisoft PhotoScan.
This study proposes a new method using Aerial Photogrammetry techniques to create an illuminance map and 3D data model for the evaluation of night-time road environment lighting condition by integrating image-derived illuminance value of the road to assess the limitations and possible enhancements.

The result of this study will provide pertinent government agencies a way of mapping and evaluating road lighting. Mapping will aid the enforcement of guidelines that promote safety for both road users and pedestrians.

The selected research area is at the National Science Complex (NSC). Located at $14^{\circ} 38^{\prime} 59^{\prime \prime} \mathrm{N}, 121^{\circ} 4^{\prime} 18^{\prime \prime} \mathrm{E}$. The area includes the Institute of Mathematics and College of Science Administration buildings, as well as the CS Amphitheatre.

\section{MATERIALS AND METHODS}

The research was composed of four stages: camera calibration, image acquisition and illuminance measurement, illuminance calculation and 3D \& 2D mapping of the road, and validation of the calculated illuminance.

\subsection{Camera Calibration}

The calibration defines which digital output value relates to which illuminance input signal. In creating the calibration curve for the channels of camera and illuminance value, both the drone and the lux meter were placed on a light box. The measurements from both camera and lux meter were simultaneously recorded and were plotted. The camera has to be calibrated first prior to illuminance measurement as a universal requirement for photogrammetric applications.

Photometric calibration was done to determine the relation of color values with illuminance. In a specific exposure setting, a 
set of images with known RGB pixel were acquired. An alternative light box was used as an integrating sphere to create uniform circular illuminance areas (Figure 1). The lux meter and the camera sensor of the UAV were placed on the same level and records images and measures illuminance reading simultaneously.

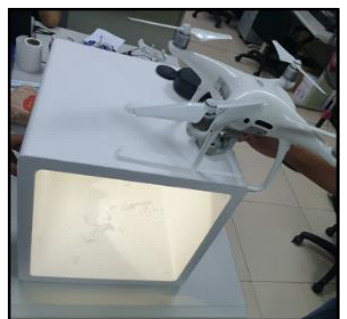

Figure 1. Use of alternative lightbox as an integrating sphere in calibration.

Using the alternative integrating sphere, different intensity levels of light were used. Video recording (30 fps) using the UAV camera was made, simultaneously with lux measurements. A very important factor is to ensure that the measured lux from the lux meter and the image produced by the UAV camera were in sync to accurately match the images with the corresponding lux measurement.

After the proper setting is determined that ensure saturation in the lightest patch, The images are evaluated with ImageJ software to obtain the R, G, B values at specific pixels. Photopic luminance value ND is also computed for calibration curve using Equation 1. ND also represents the relative luminance value (Vaaja et al, 2017). Digital output levels from each camera channels were plotted against illuminance reading from lux meter and a line was fitted.

$$
\mathrm{Nd}=0.2162 \mathrm{R}+0.7152 \mathrm{G}+0.0722 \mathrm{~B}
$$

\subsection{Image Acquisition and Illuminance Measurement}

Markings along the road were placed on both boundary sides in between boundary side, centreline of the road, and points in between them. These points served as a point to where illuminance was measured using lux meters be used later for regression modelling and validation.

Table 1. Flight acquisition plan and camera parameters used in UAS survey.

\begin{tabular}{|l|l|}
\hline Type & Manual \\
\hline Altitude & $30 \mathrm{~m}$ \\
\hline Camera Angle & $90^{\circ}$ \\
\hline ISO & 400 \\
\hline Aperture & 2.8 \\
\hline Shutter Speed & $1.8^{\prime \prime}$ \\
\hline
\end{tabular}

For image acquisition, the camera parameters and flight acquisition settings used were tabulated in Table 1 . These settings enabled illuminance values of under 15 lux with maximum dynamic range to be captured. Using DJI Phantom Pro 4, overlapping photos in JPEG format were taken along a portion of a road in National Science Complex during night between $8 \mathrm{pm}$ to $11 \mathrm{pm}$. The flight plan used in the acquisition is shown in Figure 2.

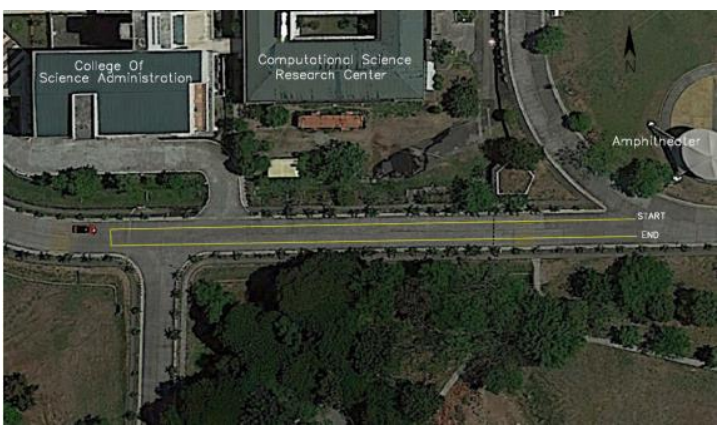

Figure 2. Flight Plan on the subject area.

\subsection{Illuminance Calculation, 3D, 2D Mapping and Validation}

2.3.1 3D and 2D mapping using Pix4D software: Using Pix4D Mapper Software, the first step in generating the 3D model was the Initial Processing. Keypoints were extracted from images and matched with each other across overlapping images. Next step was the point densification. This step increases the density of 3D points of the 3D model computed in the initial processing. The generated point cloud was exported as XYZ file consisting of $\mathrm{X}, \mathrm{Y}, \mathrm{Z}$ position and color information for each point. The last step in producing the 3D model yielded the 3D Textured Mesh, textures from the images are applied to the mesh model generated from the point cloud.

\subsubsection{Illuminance Calculation using 3D Point Cloud} Values: Using the interface of Pix4D, coordinates of 3 point clouds around each mark were taken and their corresponding RGB values were obtained and matched from the XYZ file of the 3D model output. The RGB values were averaged from the 3 point clouds color values to correspond with the measured illuminance value of the mark. Each of the RGB values, as well as the computed photopic luminance value ND, were plotted against the corresponding illuminance a line was fitted to each scatter plots to develop regression models.

\subsection{Validation of Calculated Illuminance}

The illuminance value calculated from the point cloud was compared with the illuminance measurement obtained from the markings established by the researcher using a lux meter. The best regression model was identified using different statistical tests and mode of analysis. R-squared, RMSE, Percent error and P-Bias value were used to statistically evaluate the relationship between calculated and measured value as descriptions of the data as leave one out cross validation method was used. Residuals and the percent error for each mark points in the model generated were plotted and analysed.

\subsection{Visualizing Illuminance in 3D and 2D model}

Having selected the best regression model, illuminance values of each 3D point were calculated. The XYZ file of the 3D model which contains the coordinates and corresponding RGB values were converted to another XYZ file containing the same coordinates and the corresponding computed illuminance value using the selected regression model. Using Cloud compare, an 
open source point cloud processing software, the researcher created the models.

\section{RESULTS AND DISCUSSION}

\subsection{Calibration}

After obtaining the images, and recorded values of illuminance from lux meter, the values of average pixel values were plotted against the corresponding illuminance value.

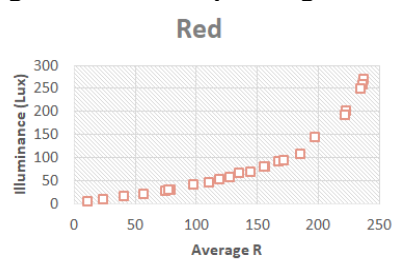

(a)

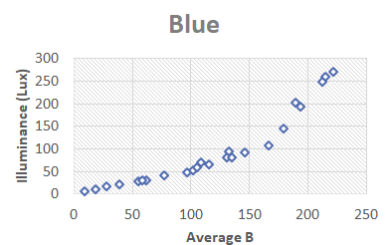

(c)

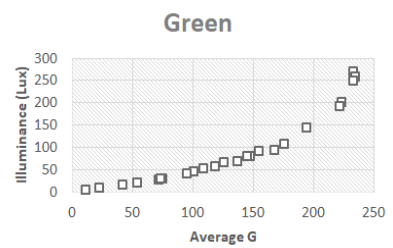

(b)

ND

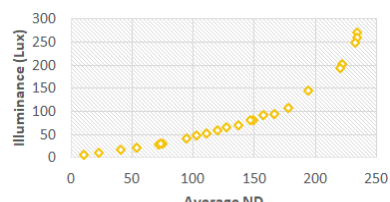

(d)
Figure 3. Scatter plot of calibration curve of (a) average red digital number (DN) vs illuminance (b) average green DN vs. illuminance (c) average blue DN vs. illuminance (d) average ND vs. illuminance.

Figure 3 shows the calibration curve of the camera channels and the photopic luminance value ND against the illuminance value (measured in lux). The calibration curve of red, green and ND shows a smooth monotonic curve. It can also be observed that the curvature of the trend increases as the value of illuminance increases. During reconnaissance, the ranges of values of illuminance are known to be less than 15 lux. Due to limited number of points, illuminance values of up to 60 lux, which is four times that of 15 lux, is plotted in Figure 4. (a)

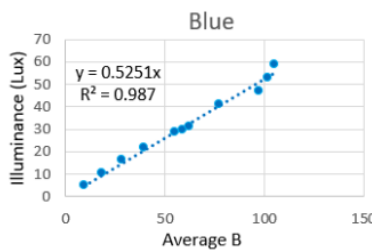

(c)

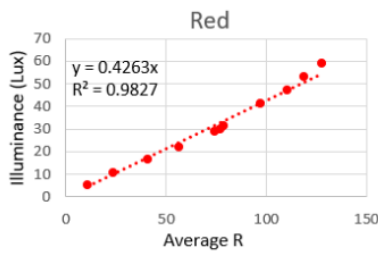

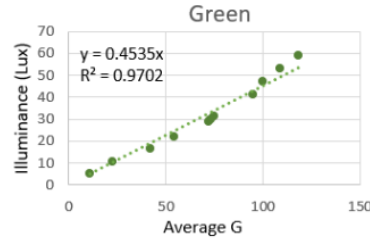

(b)

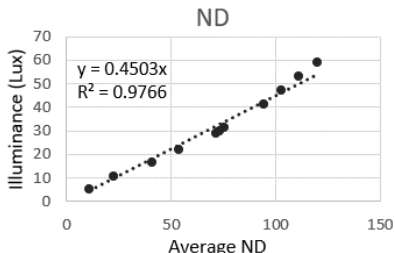

(d)
Figure 4. Scatter plot of low-level illuminance calibration curve of (a) average red DN vs illuminance (b) average green DN vs. illuminance (c) average blue DN vs. illuminance (d) average ND vs. illuminance.

The result of the calibration curve shows a good relationship between the measurements obtained from both instruments-the drone and the lux meter and can be represented in linear regression. Using the same instruments, the same relationship between the pixel values and the illuminance is expected to exhibit similar trend in different area.

\subsection{D Modelling}

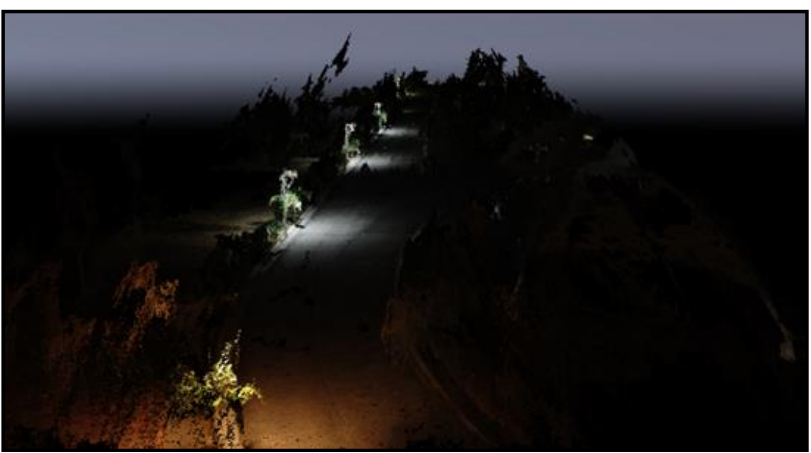

Figure 5. 3D Model of the subject area.

Figure 5 shows the 3D point cloud model of the subject area from Pix4D. The output is processed based on the images and their respective settings set during image capturing. Visually, the model captures the scenery even with low lighting. It shows that the set camera parameters and flying height during image acquisition can provide a visually accurate $3 \mathrm{D}$ model of scenery at this level of lighting during night-time.

\subsection{Statistical Analysis of Linear Regression Model of Road Surface Illuminance}

After obtaining the RGB values of the marks from the point cloud, it is plotted against the measured illuminance in a scatter plot. A linear regression model is applied to reconstruct the illuminance for a direct relationship between point cloud color value and illuminance.

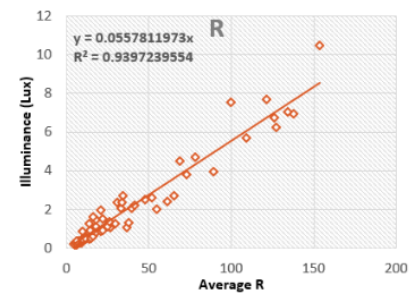

(a)

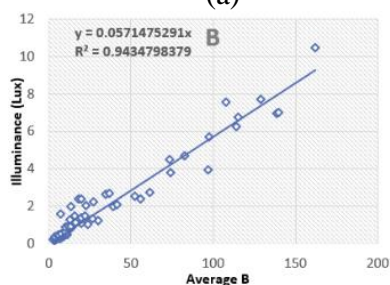

(c)

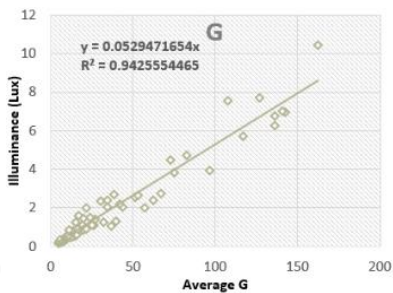

(b)

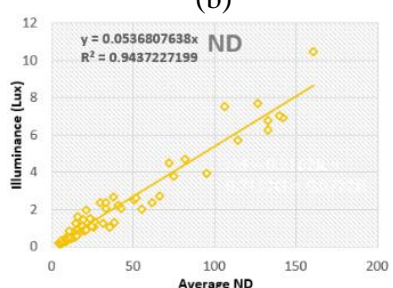

(d)
Figure 6. Scatter plot and trend line of (a) average red DN vs illuminance (b) average green DN vs. illuminance (c) average blue DN vs. illuminance (d) average ND vs. illuminance

In this study, the equation function for the UAV that is using is computationally determined in the channels RGB and ND are as follows:

$\begin{array}{lll}\text { R channel: } & \mathbf{Y}=0.0557811973 \mathbf{X} \\ \text { G channel: } & \mathbf{Y}=0.052947165 \mathbf{X} \\ \text { B channel: } & \mathbf{Y}=0.057147529 \mathbf{X}\end{array}$


ND function: $\quad \mathbf{Y}=0.053680763 \quad \mathbf{X}$

Where $\mathrm{X}$ represents the corresponding point cloud value and $\mathrm{Y}$ represents the illuminance value. To further the analysis of the regression model, R^2, RMSE, Average Percent Error, and Pbias were tabulated in Table 2 for each regression model.

Table 2. Comparison of Quantitative Statistics of the all channel of camera red, green, blue and ND function against measured illuminance.

\begin{tabular}{|l|ll|l|l|l|}
\hline \multicolumn{2}{c}{$\mathbf{R}^{\wedge} \mathbf{2}$} & RMSE & $\begin{array}{c}\text { Average } \\
\text { \% Error }\end{array}$ & $\begin{array}{l}\text { P-bias } \\
(\boldsymbol{\%})\end{array}$ & Description \\
\hline $\mathbf{R}$ & 0.939 & 0.555 & 29.038 & 2.268 & $\begin{array}{l}\text { overestimation } \\
\text { bias }\end{array}$ \\
\hline G & 0.942 & 0.542 & 25.109 & 1.539 & $\begin{array}{l}\text { overestimation } \\
\text { bias }\end{array}$ \\
\hline B & 0.943 & 0.538 & 20.798 & -4.983 & $\begin{array}{l}\text { underestimation } \\
\text { bias }\end{array}$ \\
\hline ND & 0.943 & 0.537 & 25.115 & 1.348 & $\begin{array}{l}\text { overestimation } \\
\text { bias }\end{array}$ \\
\hline
\end{tabular}

Table 2 shows that all the channels of the camera-red, green, and blue, presents good linearity when plotted against illuminance with R-squared values from 0.93 to 0.94 . The use of the photopic luminance value is common when representing illuminance value in a photograph, and to test its applicability in this research, it is also plotted against the illuminance values and is denoted as ND.

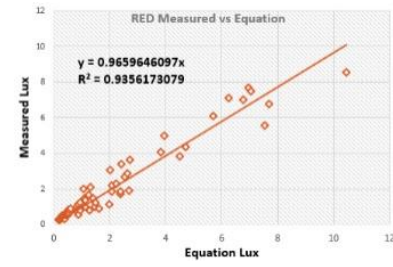

(a)

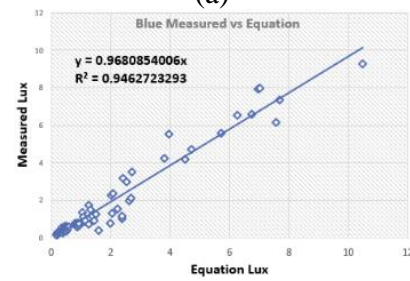

(c)

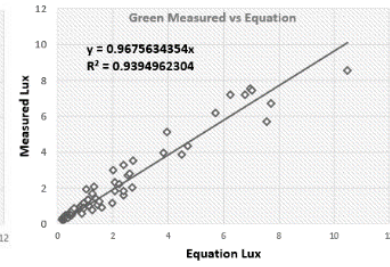

(b)

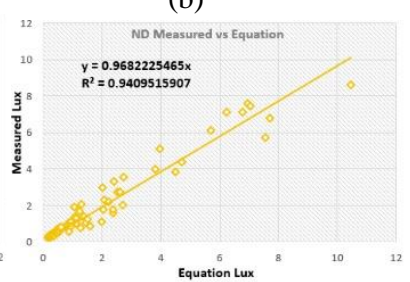

(d)
Figure 7. Scattered plot of computed illuminance vs. measured illuminance using regression model of (a) red (b) green (c) blue (d) ND.

Figure 6 shows good linearity of color values with the illuminance. It also shows that the R-squared of the ND is the highest thus, the most fitted for the linear model to the set of observation data. One factor that was considered was the Root mean squared error where ND function has the lowest value thus it has the least error from the regression line data points are. However, in calculating the average percentage error the blue channel has the least percentage error in considering the whole observation data. With this, another method to quantify the fit of the data was used. Percent bias (PBIAS) where this measures the average tendency for the regression model to overestimate or underestimate the actual values. Lower value of Pbias means more accurate model. (Bigiarini, n.d.) In this case, ND function has the lowest magnitude value which means it produced an accurate model equation and as observed, R, G channel have a positive PBIAS value which means that the values created tends to be larger than the measured values. Using the regression model, the computed illuminance values are plotted against the measured illuminance value.

To visually test the fit of the model, a scatter plot of calculated values against the measured value was created, as can be seen in Figure 7. The model is a good fit if the points lie on the 45-degree line or has a slope close to 1 . To support this, a linear trend line was created with 0 as its intercept. It can be observed in Table 3 that the slope of the trend line of all model is close to 1 representing a good estimate of the model on illuminance

Table 3. Statistics of Calculated Illuminance vs. Measured Illuminance.

\begin{tabular}{|lccc|}
\hline $\begin{array}{l}\text { Channe } \\
\text { l }\end{array}$ & \multicolumn{1}{c}{ Slope } & \multicolumn{1}{c}{ R-squared } & \multicolumn{1}{c}{ RMSE } \\
\hline R & 0.9660 & 0.9356 & 0.5557 \\
\hline G & 0.9676 & 0.9395 & 0.5425 \\
\hline B & 0.9681 & 0.9463 & 0.5381 \\
\hline ND & 0.9682 & 0.9410 & 0.5370 \\
\hline
\end{tabular}

To observe the trend of all regression model, line graph of all points of increasing illuminance were plotted against their corresponding illuminance value.

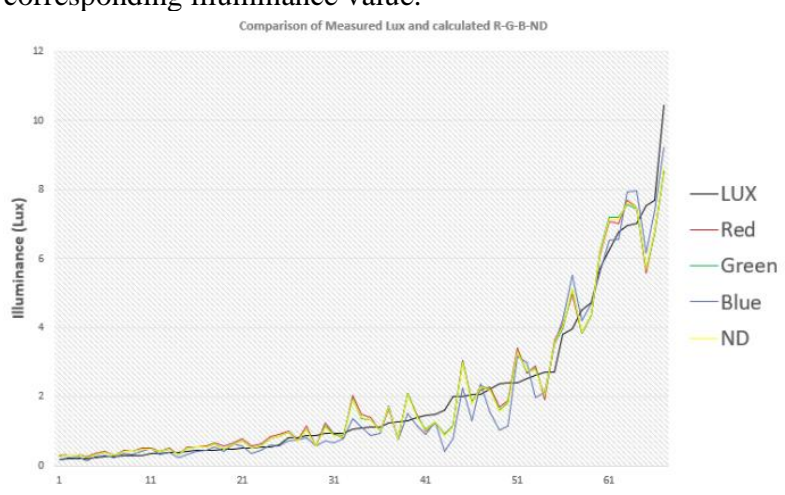

Figure 8. Line graph of illuminance values estimated using regression models.

The calculated values of all regression models show similar trend as can be seen in Figure 8. The values from blue, having similar trend with other models, is shifted generally lower than other models. To determine the difference between each model, the difference between $\mathrm{R}^{\wedge} 2$, RMSE and average percent error were tabulated in Table 4.

Table 4. Summary of statistical difference between each model.

\begin{tabular}{|c|c|c|c|c|c|c|}
\hline & R-G & R-B & R-ND & G-B & G-ND & B-ND \\
\hline$R^{\wedge} 2$ & 0.0028 & 0.0038 & 0.0040 & 0.0009 & 0.0012 & 0.0002 \\
\hline RMSE & 0.0132 & 0.0176 & 0.0188 & 0.0044 & 0.0055 & 0.0012 \\
\hline $\begin{array}{l}\text { Ave.\% } \\
\text { Error }\end{array}$ & 3.9292 & 8.2404 & 3.9235 & 4.3112 & 0.0057 & 4.3169 \\
\hline
\end{tabular}


With the results of quantitative statistics of the whole data from Table 2, the researcher considered the differences between the quantitative statistics and appeared to have a relatively small difference in R-squared and RMSE. Having a range from 0.00024 to 0.0028 value difference of $\mathrm{R}$-squares between the channels which indicates that the degree of collinearity between simulated and measured data equations produced are significantly the same. The RMSE resulting from all channels including ND are not significantly different with each other having an only difference of at most up to hundredths digit. However, the average percent error has a difference between 0 to $8 \%$ that shows that there have distinct data from each other. To elaborate the results, the chart (Figure 8) is divided into three parts; less than 1 lux, 1 to 4 lux and greater than 4 lux.

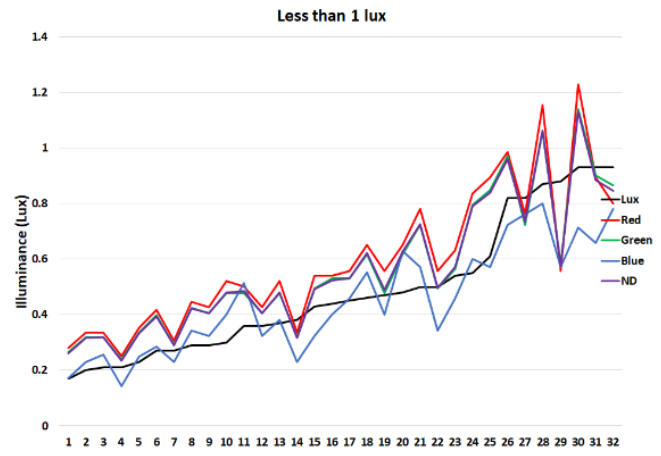

Figure 9. Line graph of illuminance values of all regression model for less than 1 lux. 1 to 4 lux

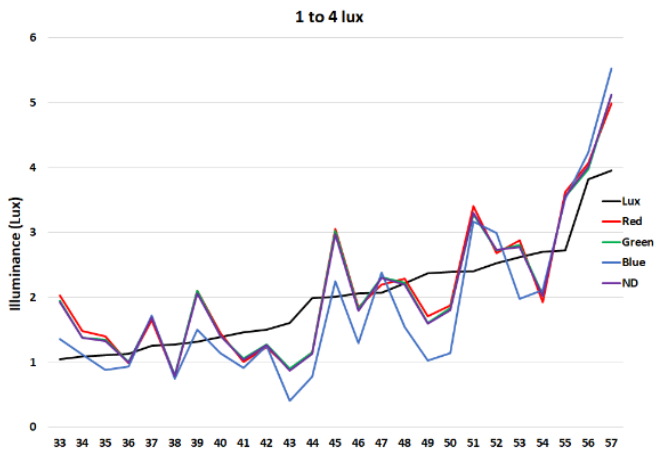

Figure 10. Line graph of illuminance values of all regression model for between 1 to 4 lux. Greater Than 4 Lux

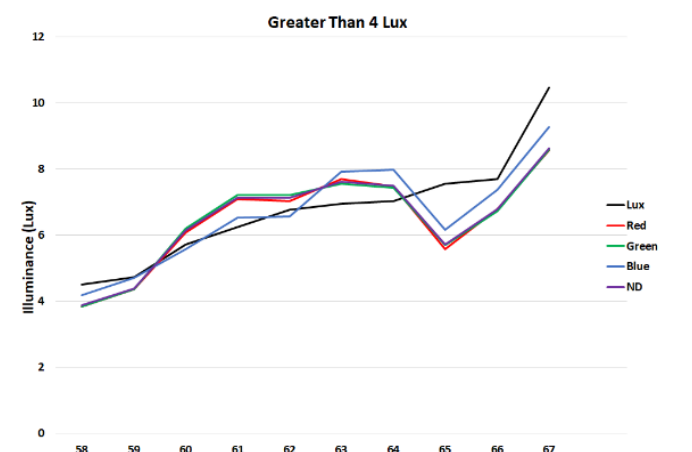

Figure 11. Line graph of illuminance values of all regression model for greater than 4 lux.

Figure 9 to 11 shows the trend of illuminance values of all regression model per range. In Figure 9, it can be visually observed that the values obtained from the regression model of red, green and ND is generally higher than that of actual values. In Figure 10, the values obtained from regression model of blue is generally lower than the actual values. In Figure 11, the trend of all regression model is smoother than that of the trends for smaller ranges of values.

Table 5. Statistical comparison of RMSE per range of values of illuminance.

\begin{tabular}{|c|c|c|c|c|}
\hline $\begin{array}{l}\text { Ranges } \\
\text { (Lux) }\end{array}$ & $\mathbf{R}$ & G & B & ND \\
\hline Less than 1 & 0.1685 & 0.1358 & 0.1141 & 0.1357 \\
\hline $1-4$ & 0.6069 & 0.5930 & 0.7327 & 0.5965 \\
\hline $\begin{array}{l}\text { Greater } \\
\text { than } 4\end{array}$ & 1.0283 & 1.0167 & 0.7458 & 0.9916 \\
\hline Less than 3 & 0.4042 & 0.3812 & 0.4511 & 0.3831 \\
\hline $\begin{array}{l}\text { Greater } \\
\text { than } 3\end{array}$ & 0.9876 & 0.9885 & 0.8270 & 0.9681 \\
\hline
\end{tabular}

Table 6. Statistical comparison of average percent error per range of values of illuminance.

\begin{tabular}{|c|c|c|c|c|}
\hline $\begin{array}{l}\text { Ranges } \\
\text { (Lux) }\end{array}$ & $\mathbf{R}$ & G & B & ND \\
\hline Less than 1 & 34.8597 & 27.6425 & 17.6751 & 27.6837 \\
\hline $1-4$ & 28.4256 & 27.0293 & 29.9829 & 27.1556 \\
\hline $\begin{array}{l}\text { Greater } \\
\text { than } 4\end{array}$ & 11.9434 & 12.2037 & 7.8301 & 11.7945 \\
\hline Less than 3 & 32.6072 & 27.7593 & 22.9930 & 27.8184 \\
\hline $\begin{array}{l}\text { Greater } \\
\text { than } 3\end{array}$ & 12.6822 & 12.9639 & 10.7384 & 12.7248 \\
\hline
\end{tabular}

Table 7. Statistical comparison of P-bias per range of values of illuminance.

\begin{tabular}{|c|c|c|c|c|}
\hline $\begin{array}{l}\text { Ranges } \\
\text { (Lux) }\end{array}$ & $\mathbf{R}$ & G & B & ND \\
\hline Less than 1 & 22.6204 & 16.4474 & -7.2703 & 16.2383 \\
\hline $1-4$ & 5.3124 & 4.6556 & -8.2204 & 4.0225 \\
\hline $\begin{array}{l}\text { Greater } \\
\text { than } 4\end{array}$ & -4.6532 & -4.1867 & -2.0642 & -4.0451 \\
\hline Less than 3 & 8.4527 & 6.1663 & -12.5044 & 5.4807 \\
\hline $\begin{array}{l}\text { Greater } \\
\text { than } 3\end{array}$ & -2.4692 & -2.0056 & 0.7787 & -1.8164 \\
\hline
\end{tabular}

Tables 5 to 6 shows values for RMSE, average percent error and Pbias. It can be observed that the RMSE increases as the range increases while average percent error decreases. This shows that even when error increases in higher range, its error relative to the illuminance value is lower. In all the table, it can be observed that the illuminance value by the linear regression model of Blue generally exhibits smallest error through these statistical quantities. Even though the linear regression of green is better than that of blue in range of 1-4 lux, the difference between their values is small. In Table 7, it can be observed that Pbias of regression model of red, green, and ND is positive for range of less than 1 lux and between 1 and 4 lux. This shows that these 
regression model tends to underestimate the value of illuminance at these range. Blue, in all ranges shows negative P-bias in all ranges, meaning that this regression model tends to underestimate the value of illuminance in all ranges. It can also be observed that for higher values, specifically the range greater than 4 lux, all the regression models tend to underestimate the value of illuminance. Additionally, based on European Committee for Standardization (CEN), where Philippines mostly base their guidelines, our study area where there is low traffic and low crime risk, we selected the minimum illuminance of 3 lux. Similar trends for RMSE and average percent error with the previous ranges where smaller range has smaller RMSE and higher range has lower average percent error.

\subsection{Validation}

To assess the accuracy of the model, leave-one-out cross validation (LOOVC) was performed. After obtaining values of residual on each point from LOOVC, it is plotted together with the residual from the regression model using all data. This is to show the difference of each model on the LOOVC and the created model from all data.
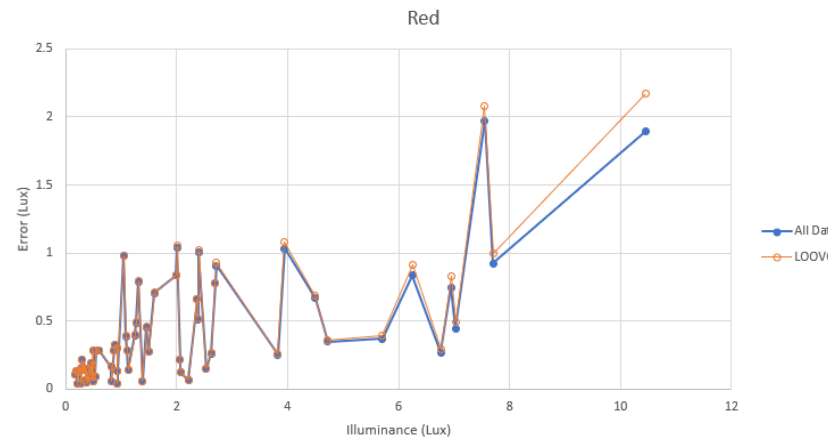

Figure 12. Absolute residual plot from all data and LOOVC of regression model of red.

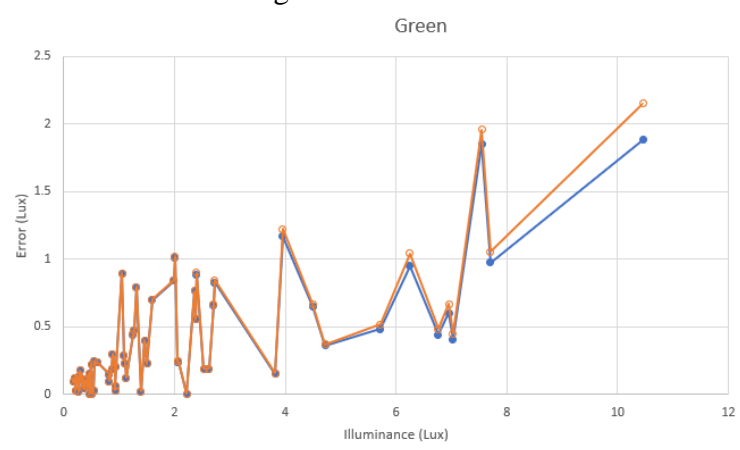

Figure 13. Absolute residual plot from all data and LOOVC of regression model of green

Blue

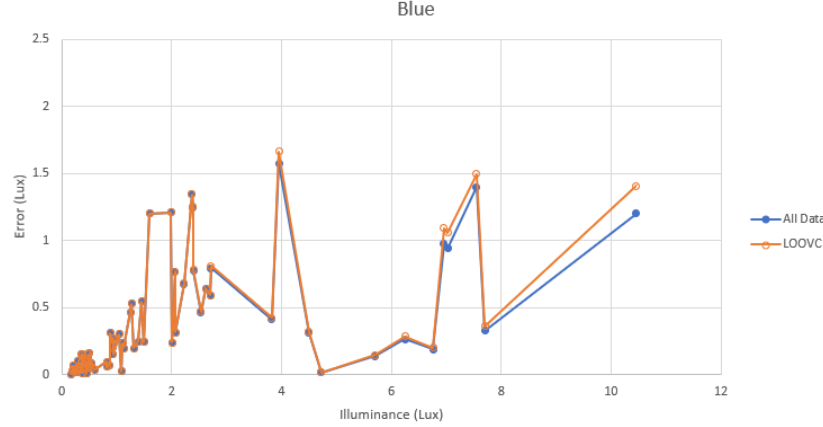

Figure 14. Absolute residual plot from all data and LOOVC of regression model of blue.

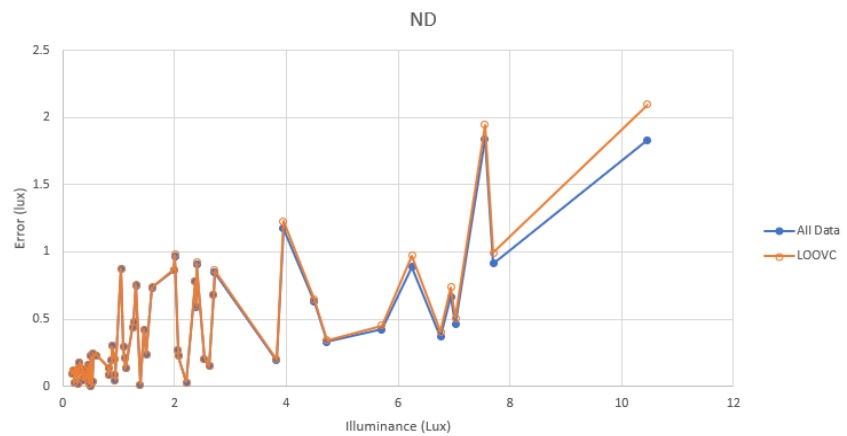

Figure 15. Absolute residual plot from all data and LOOVC of regression model of ND.

Figure 12 to 15 shows that the 2 lines are similar with each other varying only at higher value of illuminance. Visually, this can show that the researchers' model is similar to the models from LOOVC and can be validated by this method.

Table 8. Average slope and RMSE of linear regression model from LOOVC.

\begin{tabular}{lllll}
\hline LOOVC & Red & Green & Blue & ND \\
\hline $\begin{array}{l}\text { Average } \\
\text { Slope }\end{array}$ & 0.055779 & 0.052946 & 0.057147 & 0.053679 \\
\hline RMSE & 0.586326 & 0.573801 & 0.561421 & 0.567449 \\
\hline
\end{tabular}

Table 9. Slope and RMSE of linear regression model from all data.

\begin{tabular}{lllll}
\hline All Data & Red & Green & Blue & ND \\
\hline $\begin{array}{l}\text { Average } \\
\text { Slope }\end{array}$ & 0.055781 & 0.052947 & 0.057148 & 0.053681 \\
\hline RMSE & 0.555712 & 0.542502 & 0.538119 & 0.536962 \\
\hline
\end{tabular}

Table 8 and Table 9 shows the similarity of the model from LOOVC and the researchers' model. Each of the researchers' model, as represented by the slope, shows similar values with the average value of all models from LOOVC. Their RMSE shows similar values as well, with both values less than 0.6lux. With these, the linear regression model using blue channel was used to calculate for illuminance value.

\subsection{D and 2D Illuminance Value Model}

Using the linear equation of camera channel Blue, 3D model was created as shown in Figure 16 to visualize the extent of lux for the road environment. The researchers used the interval of greater and less than 3 lux in Figure 16.a at which the minimum value of lux is 3, specific for the study road area as CEN (European Committee for Standardization (CEN, French: Comité Européen de Normalisation) imposed. And Figure 16.b having an interval of less than 1,1-4, and greater than 4 which quantified the critical lux which is under the interval 1-4. 


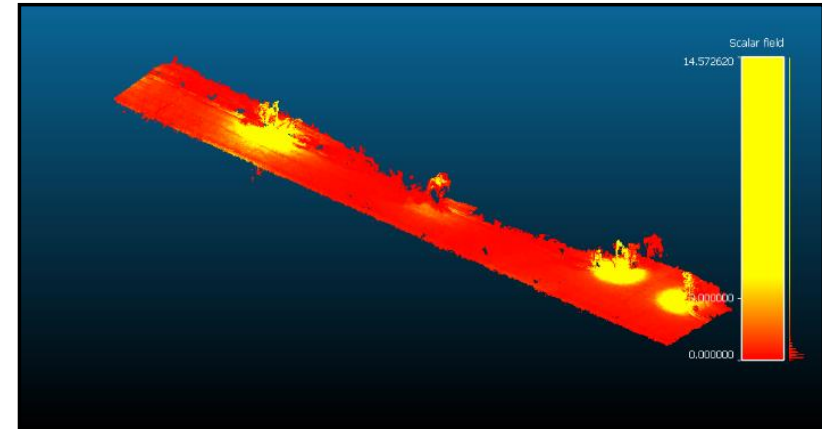

(a)

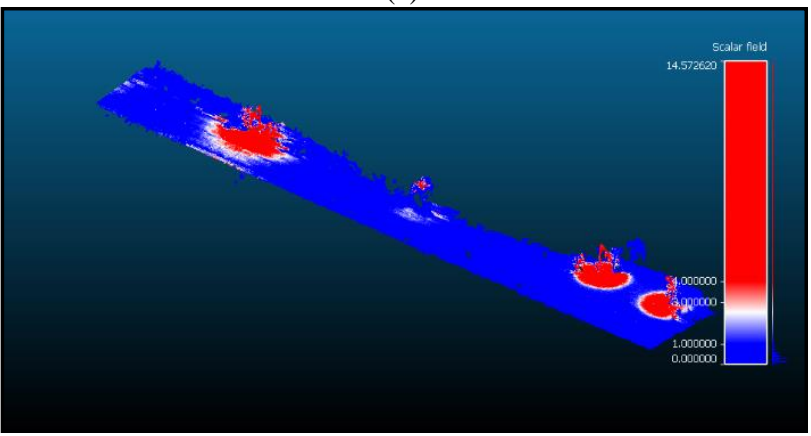

(b)

Figure 16. Illuminance data integrated 3D model (a) having an interval of less than and greater than 3 (b) having an interval of less than 1,1-4, and greater than 4 . The color bar indicates the luminance values in lux

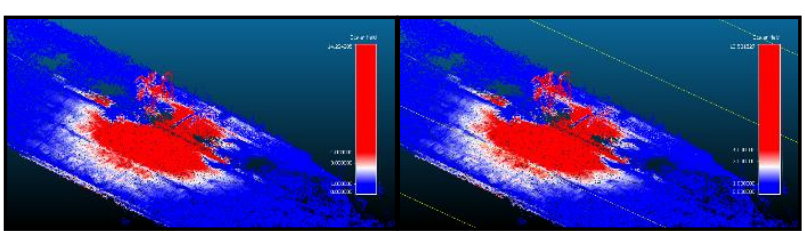

(a) (b)

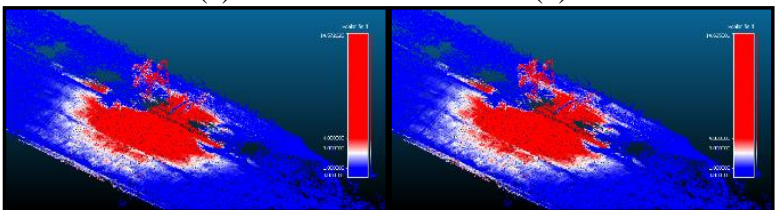

(c)

(d)

Figure 17. Illuminance data integrated 3D point cloud (a) red, (b) green, (c) blue, (d) function ND.

The researcher created the illuminance model of each channel as linear model regression equation function for the UAV was used. Figure 17 visually shows the difference between each channel model where there is a small variation at high lux and consistency in lower lux value.

For the visualization and analysis of road illuminances 2D mapping was also produced following the same set of intervals in 3D model which are less than 1lux, 1-4lux, and greater than 4lux, as shown in Figure 18.

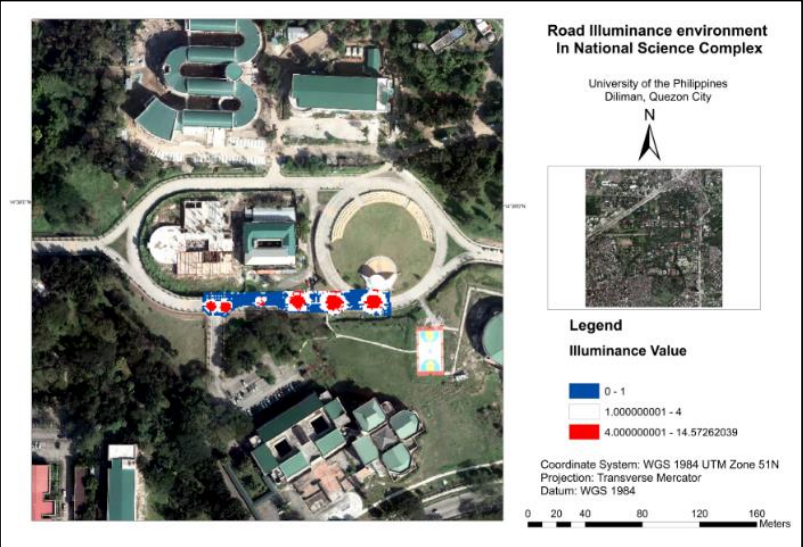

Figure 18. 2D Illuminance mapping of the road area using linear function channel Blue.

\section{CONCLUSION}

The use of photogrammetry through UAV in measuring illuminance values on the road presented an alternative way of measuring and mapping technique. For the visualization and analysis of road surface illuminances, this method is an improvement over the method currently in use which is the measurement of illuminance at point locations using lux meter. Illuminance analysis was conducted on images to create a $2 \mathrm{D}$ map and a 3D model of illuminance distribution.

A detailed road environment model with illuminance values was obtained using Aerial Photogrammetric Technique. The illuminance values of the RGB images were calibrated with a reference illuminance source, and the calibration curve between camera channels and illuminance showed linear relationship at low level lightings. And linear regression model of each channel of camera, as well as ND, can be used to calculate the illuminance at low level lighting to produce a 2D and 3D model.

Being able to map the night-time road environment have applications that include an inventory of lighting fixtures, other road furniture, visualizing the extent of lighting area for road condition which allows for more resource-efficient safety management and maintenance planning.

\subsection{Recommendation}

This research focuses on measurement and mapping of illuminance through photogrammetry, in which camera settings are set constant and road surface reflectivity variations are not considered. With this research concluding that aerial photogrammetry can be used as an alternative way of mapping illuminance, it is recommended for future researches to include comparative studies on different camera settings on the accuracy of measuring lighting quantities. Besides illuminance, luminance is also used for roadway lighting evaluation which considers the reflectivity of the surface. Spotmeter is an expensive device which measures luminance. With this, application of aerial photogrammetry on measuring and mapping luminance is also recommended.

\section{ACKNOWLEDGEMENTS}

The researchers would like to thank Engr. Christian Candido, Engr. Ayin Tamondong, and other ENVISAGE Research Laboratory members for sharing equipment and for teaching how to operate them. 


\section{REFERENCES}

Agriculture Drone Services. n.d. My Drone Services. Retrieved from https://mydroneservices.com/our-services/agriculturalservices/

Bigriarini, M., n.d.. Percent Bias. R Documentation. Retrieved from

https://www.rforge.net/doc/packages/hydroGOF/pbias.html

Department of Energy., 2017. Roadway Lighting Guidelines.(n.d.). Retrieved from https://www.doe.gov.ph/sites/default/files/pdf/energy_efficienc y/doe-road-light-2017.pdf

Hiscocks, Peter D. , 2014. "Measuring Luminance with a Digital Camera”. Syscomp Electronic Design Limited, 2014. Retrieved from https://www.ee.ryerson.ca/ phiscock/astronomy/lightpollution/luminance-notes-2.pdf

International Commission on Illumination. 2010. Lighting of Roads For Motor and Pedestrian Traffic. CIE Technical Report. 2nd Edition.

SBL., July 12, 2015. A Brief Introduction to Photogrammetry and Remote Sensing. GIS LOUNGE. Retrieved from https://www.gislounge.com/a-brief-introduction-tophotogrammetry-and-remote-sensing/

Vaaja, Mattimm et.al., 2015. "Luminance-Corrected 3D Point Clouds for Road and Street Environments". Remote Sensing.; 7(9): 11389-11402. Retrieved from http://www.mdpi.com/2072$4292 / 7 / 9 / 11389$

Vaaja, Matti, et al., 2017. Camera Preparation and Performance for 3D luminance mapping of road environments The Photogrammetric Journal of Finland, Vol. 25, No. 2. doi:10.17690/017252

Whitmore, George., n.d. CURRENT DEVELOPMENTS IN PHOTOGRAMMETRY IN THE UNITED STATES. Retrieved from https://www.asprs.org/wpcontent/uploads/pers/1952journal/jun/1952_jun_598-603.pdf 